\title{
Publication of fake journals raises ethical questions
}

One of the world's largest publishers of medical literature, Elsevier, has come under fire for having distributed marketing periodicals that many people say deceptively resembled peer-reviewed journals.

Since the 1980s, doctors have commonly received publications designed to promote pharmaceutical products through a mix of studies, opinion pieces and simple advertisements. Elsevier currently has a subsidiary, Excerpta Medica, that specializes in such publications.

In a statement released on 7 May, Michael Hansen, chief executive officer of Elsevier's Health Sciences Division, acknowledged that, between 2000 and 2005, an Australian office of Elsevier had distributed promotional periodicals that were packaged as journals, without disclaimers clearly marking them as industry-sponsored products.

Elsevier, headquartered in Amsterdam, claims that the distributions were isolated incidents decided by a group of individuals who have since left the company. "There's always been a rule within Elsevier, you can title sponsored publications under headings like 'supplements' or 'compilation products' - as long as they're clearly marked as being sponsored products" and not as 'journals', an
Elsevier spokesman told Nature Medicine.

The recent controversy kicked off when The Australian newspaper and The Scientist magazine reported on the existence of the Australasian Journal of Bone and Joint Medicine. The journal, an advertorial publication resembling a peer-review journal, came to light in April during a civil suit brought against Merck and its Australian subsidiary by a man who suffered a heart attack in 2003 while taking the drug Vioxx.

During the trial, George Jelinek, a member of the World Association of Medical Editors, testified that the publication would be commonly mistaken for a peer-reviewed journal, even though it was sponsored by Merck and contained only articles that drew positive conclusions about Merck products.

Additionally, the publication listed an "honorary editorial board." One of the listed members, Australian arthritis specialist James Bertouch, reportedly testified that, until recently, he did not know of the journal's existence.

An internal review at Elsevier in May uncovered five other sponsored publications that resembled peer-review journals in looks: the Australasian Journal of General Practice, the Australasian Journal of Neurology, the Australasian Journal of Cardiology, the Australasian Journal of Cardiovascular Medicine and the Australasian Journal of Clinical Pharmacy. There were also at least 20 other journal titles that the Australian group had registered with WorldCat, a journal search engine, but never apparently used.

"These are obviously extreme scenarios that anyone can take a look at and see as being wrong, but they reflect an almost deceptive undercurrent in the way doctors are being presented information." says Allan Coukell. Coukell directs the Pew Prescription Project, a nonprofit organization funded by the Pew Charitable Trusts to promote the recommendations of a 2006 article that criticized how drugs are marketed to doctors (J. Am. Med. Assoc. 295, 429-433; 2006).

These types of advertorial publications can present biased studies and opinion pieces in a way that gives them an undue air of authority, he adds, much like a television advertisement that is presented in the form of a newscast.

"Don't doctors already have enough of a challenge wading through the information sent to them without purposely making it tricky?" Coukell says.

Stu Hutson, Gainesville, Florida

\section{Malaria drug delivery program launches amid skepticism}

An innovative financial scheme launched in April aims to reduce the cost people in poor countries pay for effective malaria treatment. The program's key feature, heavily subsidizing the private market, is the brainchild of a Nobel laureate in economics. But critics, including some aid officials in the United States, charge that the program is questionable use of scarce funds.

Much of the initial $\$ 225$ million budget for the program, dubbed the Affordable Medicines Facility for malaria (AMFm), comes from UNITAID, a drugbuying consortium linked to the World Health Organization.

AMFm will press drug companies to reduce the price they charge nongovernmental buyers for artemisinin combination therapies from $\$ 4$ per treatment course to $\$ 1$-at which point

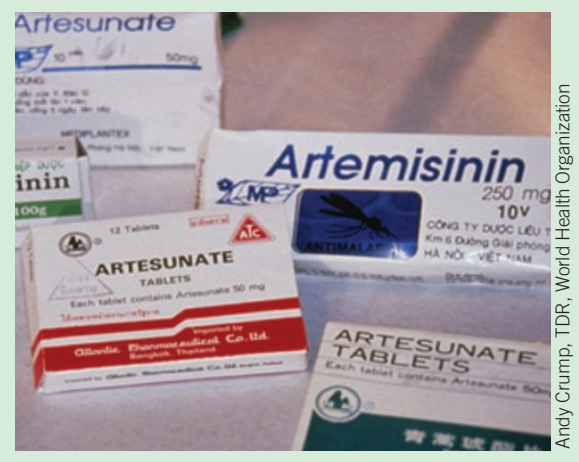

Subsidize this: Antimalarial drugs funded

AMFm will pay the manufacturer a 95cent subsidy. The ultimate aim is to drive down the retail cost of the drugs, often sold at small village stores, from between $\$ 5$ and $\$ 8$ to below 50 cents.

The idea for AMFm was outlined in a 2004 report from the Institute of Medicine, written by a committee headed by Nobel Prize winner Kenneth Arrow at Stanford University in Palo Alto, California. Arrow says that the private market approach skirts the difficulty of distributing malaria drugs through centralized government-run systems.

The United States has not contributed funds. Bernard Nahlen, Deputy Coordinator at the US-based President's Malaria Initiative says that the handful of pilot studies on the approach have not proven its effectiveness: "we do not actually know that this [AMFm] is going to work in the way we think it will."

Critics are also concerned about provisions in the scheme that allow subsidies for artemisinin monotherapy, which could foster drug resistance.

Nayanah Siva, London 